\title{
The Effect of Early Childhood Sexual Abuse on Mental Health Among Postpartum Women Visiting Public Health Facilities in Bahir Dar City, Ethiopia: Multicenter Study
}

This article was published in the following Dove Press journal:

International Journal of Women's Health

\author{
Habte Belete id \\ Eyaya Misgan ${ }^{2}$ \\ Muhabaw Shumye Mihret iD $^{3}$ \\ 'Psychiatry Department, College of \\ Medicine and Health Sciences, Bahir Dar \\ University, Bahir Dar, Ethiopia; \\ ${ }^{2}$ Gynecology and Obstetrics \\ Department, College of Medicine and \\ Health Sciences, Bahir Dar University, \\ Bahir Dar, Ethiopia; ${ }^{3}$ Department of \\ Clinical Midwifery, College of Medicine \\ and Health Sciences, University of \\ Gondar, Gondar, Ethiopia
}

Background: There is a scarcity of evidence regarding the effects of early childhood sexual abuse on mental health among women in Sub-Saharan Africa. The purpose of this study was to assess the proportion of postpartum depression and associated factors among postnatal women in care in public health facilities of Bahir Dar city, northwest Ethiopia. This study also aimed at evaluating the effect of early childhood sexual abuse on postpartum depression. Methods: A multicenter cross-sectional study was conducted among 988 postpartum women in care at Bahir Dar city's public health facilities. A two-stage sampling technique and interviewer administered structured questionnaire were utilized. Edinburgh Postnatal Depression Scale (EPDS) with a cutoff point of $\geq 12$ was employed to report postpartum depression. Binary logistic regression model was fitted and the level of significance was reported based on AOR with 95\% CI at p-value of $<0.05$.

Results: The prevalence of postpartum depression was $33.8 \%$ (95\% CI: 31,37$)$ and $55.3 \%$ (95\% CI: 46, 64) among all study participants and mothers having a history of childhood sexual abuse, respectively. Participants' age of $<25$ years $(\mathrm{AOR}=3.1 ; 95 \% \mathrm{CI}: 1.9,5.3)$ and 25-34 years $(\mathrm{AOR}=2.0 ; 95 \% \mathrm{CI}: 1.3,3.2)$, family size of $>5(\mathrm{AOR}=2.5 ; 95 \% \mathrm{CI}: 1.1,5.7)$, alcohol use $(\mathrm{AOR}=2.2 ; 95 \% \mathrm{CI}: 1.6,2.9)$, history of childhood sexual abuse $(\mathrm{AOR}=2.8$; $95 \% \mathrm{CI}: 1.9,4.3)$, joblessness ( $\mathrm{AOR}=1.4 ; 95 \% \mathrm{CI}: 1.1,1.9)$ and growing up with biological mothers ( $\mathrm{AOR}=0.5 ; 95 \% \mathrm{CI}: 0.4,0.8)$ have stastical significant association with postpartum depression as compared to the respective reference group.

Conclusion: A significantly higher burden of postpartum depression was observed among mothers with a history of childhood sexual abuse. Thus, controlling childhood sexual abuse and other psychosocial determinants would improve maternal mental wellness.

Keywords: Bahir Dar city, childhood sexual abuse, Ethiopia, postpartum depression

\section{Background}

Maternal mental wellness is a very essential component of women's health for better multi dimensional values within the family and the community at large. Unfortunately, it could be affected by many psychosocial stressors including Childhood Sexual Abuse (CSA). ${ }^{1}$

CSA in women is a major public health and social-welfare problem in low income countries. It has long lasting effects on mental health, drug and alcohol misuse, and risky sexual and criminal behavior in children. ${ }^{2,3}$ Even though CSA is
Department of Clinical Midwifery, College of Medicine and Health Sciences, University of Gondar, PO. Box 196, Gondar, Ethiopia

Tel +251918473798

Fax +251581110004

Email muhabawshumye@gmail.com
International Journal of Women's Health 2020:12 |27|-|28| 
associated with adult-onset depression in both genders, its incidence is more common in women than in men. ${ }^{4} \mathrm{CSA}$ is a significant early stressor that predisposes women to adult-onset depression through deregulation of brain chemistry. From this perspective, psycho- trauma mothers who had early CSA have a chance of developing late postpartum depression (PPD). ${ }^{5}$ From earlier findings, the link between CSA and higher rate of PPD had been described. ${ }^{6-9}$ Accordingly, adult mothers who had a history of early CSA had risk of fear, sexual problems, and depression in their lifespan., ${ }^{5,10,11}$ A few regional researches have reported the mental health effects of gender-based violence among women in Sub-Saharan Africa. $^{12-14}$

The prevalence of PPD varies across different countries. It ranges from $0.5 \%-60.8 \%,{ }^{15-17}$ and its rate is between $10 \%-15 \% .{ }^{18-20} \mathrm{~A}$ review report on perinatal mental disorders showcases that the magnitude of mental disorder reached up to $19.8 \%$ among postnatal mothers in low- and lower-middle-income countries. ${ }^{21}$ In Ethiopia, the pooled prevalence of PPD is $22.89 \%{ }^{22}$ On the other hand, it is reported in different settings and regions of Ethiopia to be $22.1 \%$ in Bahir Dar, ${ }^{23}$ 15.6. \% in Debre Berhan, ${ }^{24} 20.9 \%$ in Nekemite, ${ }^{25}$ and $12.2 \%$ in Sodo. ${ }^{26}$ The prevalence of PPD in some other developing countries also has been reported at $23 \%$ in India, ${ }^{27} 28 \%$ in Pakistan, ${ }^{28}$ and $34.7 \%$ in South Africa. ${ }^{20}$ In addition, the magnitude of postnatal mental illness in Zimbabwe was reported to be $16 \%,{ }^{29}$ whereas, that of the major depressive disorder at six weeks postpartum in Uganda was $6.1 \% .{ }^{30}$

In previous studies, certain risk factors of PPD were identified and reported. Accordingly, stressful life events, ${ }^{23,26,32}$ unplanned pregnancy, ${ }^{22,23,25}$ domestic/partner violence, ${ }^{23,25,33}$ poor social support, ${ }^{22,24,25}$ history of previous depression, ${ }^{22,25}$ dissatisfaction in marriage, ${ }^{22,26}$ younger age of the mother, ${ }^{32,33}$ having hospitalized child, ${ }^{23,24}$ experiencing a death of an infant or family member, ${ }^{22,24}$ low self-esteem and feeling of loneliness, ${ }^{32}$ birth of a female child, ${ }^{32}$ rural residence, ${ }^{26}$ grand multiparty, ${ }^{26}$ perinatal complications, ${ }^{26}$ a past history of abortion, ${ }^{26}$ experiencing hunger in the preceding 1 month, ${ }^{26}$ lower perceived wealth, ${ }^{26}$ history of substance use, ${ }^{25}$ being first time mother, and ${ }^{25}$ domestic decision making, ${ }^{23}$ were associated with PPD. However, these factors could be varied across settings and over time trends.

Being female is a risk factor for early CSA, and having a history of CSA is a risk factor for depression with reversed neuro-vegetative features. ${ }^{1,34}$ Women who had history of sexual abuse reported a significantly higher levels of depressive symptoms and negative life events. ${ }^{35,36}$ Existing evidence points to mothers who had a history of sexual abuse before the age of 17 years having a risk of developing depression in their adult life. ${ }^{37}$ The link of PPD and CSA has been well addressed in the developed world. However, this issue is yet to be addressed in low income countries like Ethiopia. In this regard, there might be a disparity across high and low income countries regarding the link between PPD and CSA as the socio-economical, cultural, lifestyle and responses to the unfavorable conditions and many other conditions that could vary across the population living in the two categories of countries. Although the ultimate pathophysiology of depression poses neurological bases, the underlying contributing factors could be multidimensional which would be affected by the environmental conditions. Therefore, assessing the effect of CSA on PPD in low income countries is compulsory to provide valuable evidence, and to inspire further future researches on this regard. To the best of investigators deep review, no research has been conducted in Ethiopia to answer what is the effect of CSA on PPD and other psychopaths during childbearing age. Therefore, this study was primarily intended to highlight in the area of CSA and late development of PPD among postpartum mothers visiting public health facilities in Bahir Dar city, northwest Ethiopia. In addition, the study also aimed to assess the prevalence and associated factors of PPD among the aforesaid study population in the study settings.

\section{Methods}

\section{Study Design, Period and Settings}

A multicenter institution-based cross-sectional study was conducted during March to May 2017. The study was carried out at public health facilities found in Bahir Dar city which is located in northwest Ethiopia, about 565 kilo meters away from Addis Ababa. In the city, there are six public health facilities. From which, we randomly selected three facilities namely Felege Hiwot Referral Hospital, Bahir Dar health center and Hann health center. Felege Hiwot Referral Hospital serves for average of more than 1100 postpartum mothers per month and the two health centers also each serves for an average of 500 mothers per month for routine postnatal care. 


\section{Participants}

All postpartum mothers who have visited public health facilities in Bahir Dar city for routine obstetrical care services were the source population. Those $\geq 18$ yearold women, who were at about 6-8 weeks postpartum and have visited the selected health facilities for routine obstetric cares, were included in the study. On the other hand, those mothers who were unable to communicate due to illness were excluded.

\section{Sample Size Determination, Sampling Technique and Procedures}

Sample size has been calculated using Epi Info version 7 considering the following assumptions: the prevalence of postpartum depression, $50 \%$ (as there was no previous study in the settings); confidence limit, $4 \%$, confidence level, 95\%; design effect, 1.5; and non-response rate, $10 \%$. Thus, a total sample size of 990 was obtained.

A two-stage sampling technique was utilized. First, we randomly selected three out of six health facilities as mentioned in the first paragraph of the Methods section. Then, we retrieved the data regarding the monthly cases flow in each selected health facility, allocated proportionally and calculated the K-interval. Accordingly, the interval was found to be 2 and a systematic sampling technique was applied to select eligible study participants every 2 interval till the required sample size was obtained.

\section{Method of Selection for Mothers Who Had CSA}

Participants were asked in a separated and secured room whether they experienced one or more events of CSA until the age of 18. A pretested, interviewer administered, structured, anonymous and standardized sexual abuse screening questionnaire was adapted and used. ${ }^{38,39}$ Any type of experiences of sexual abuses including sexual assault, sexual abuse by coercion or force, attempted rape, nonvaginal sexual relations by force, threat, bribery and rape were considered and the data collection was done by female Diploma nurses.

\section{Instruments}

PPD was considered when mothers scored a total of $\geq 12$ points for Edinburg Postnatal Depression Scale (EPND) screening tool. ${ }^{40}$ The EPDS was developed in 1987 by Cox, Holden and Sagovsky as a self-report questionnaire. Nowdays, the tool is used in many countries to screen for the risk of developing perinatal depression among childbearing mothers. The EPDS is validated in different African countries and the internal consistency of the EPDS (Chronbach's alpha) is $0.84 .{ }^{41}$ Participants' social support was assessed by using Oslo-3 social support scale which consists of three items. ${ }^{42}$ Current substance utilization was assessed by asking the individuals whether or not they used any substance during the last three months. Income was assessed by using relative income by asking mothers to level their own income as less than others, similar to others and better than other. Family related factors and clinical variables like history of depression, current child pregnancy (planned/ unplanned), mode of delivery, and history of abortion were assessed. To minimize the recall bias of the retrospective data, we exerted our maximum efforts. First of all, we tried to devise the questionnaire in such a way that it was prepared and ordered from simple to complex and recent to past in chronological order. The questionnaire was also translated to local language to enhance its understandability to both the data collectors and respondents. Moreover, we tested the tool by conducting a pretest. Secondly, we delivered trainings for the data collectors on the strategies of minimizing recall bias. Accordingly, the data collectors had been informed to assure that each question to be understandable clearly for the respondents prior to the respective replies; to probe for local events that could trigger the respondents' recall capacity; to offer sufficient time for the participants to recall long term memories, to refer any records or consult any other potential source of information such as family members, intimate friends and any other persons who were around at the time of event; and to use multiple sources of information like crosschecking the documented records and contacting the involved health care providers for uncertainties in documentations. In the mean time the respondents' voluntariness, privacy and confidentiality had been assured.

\section{Analysis}

Data were entered using Epi data version 3.1 and analyzed by using Statistical Package for Social Science (SPSS) version 20. Descriptive statistics were reported. Binary Logistic regression model was fitted. Both crude odds ratio (COR) and adjusted odds ratio (AOR) were computed and reported. The level of significance was claimed based on AOR, 95\% confidence interval (CI) and p-value at $<0.05$. 


\section{Results}

\section{Demographic Characteristics}

A total of 988 postpartum women completed the interview, making a response rate of $99.8 \%$. Almost one-fifth $(20.4 \%$ of the overall, $18.7 \%$ of those with CSA and $20.7 \%$ of those with no CSA) of the respondents were at less than 25 yearold. About 158 (16\%) of the overall respondents, 29 (23.5\%) of those with CSA and 129 (14.9\%) of those with no CSA were unable to read and write at the time of interview. More than half $(54.4 \%$ of the overall, $56.9 \%$ of those with CSA and $54.1 \%$ of those with no CSA) of the respondents reported that they were first married before the age of 20 years (Table 1).

\section{Psychological Related Factors}

Overall, about 273 (27.6\%) of the participants had a history of abortion with higher proportion among women with history of CSA than those with no CSA (32.5\% versus $26.9 \%)$. Poor social support was reported among 207 (21\%) of the overall respondents, 36 (29.2) of the participants with history of CSA and 171 (19.8\%) of the respondents with no history of CSA. Nearly one- sixth $(15.4 \%)$ of the general study population, nearly one-third (32.5\%) of the women with history of CSA and about oneeighth $(12.9 \%)$ of the mothers with no history of CSA reported that they fell pregnant unintentionally (Table 2).

\section{Prevalence of Postpartum Depression}

The overall prevalence of PPD was 33.8\% (95\% CI: 31, 37). Whereas, the prevalence of PPD was $55.3 \%(95 \%$ CI: 46,64$)$ among mothers who had history of CSA and 30.8\% (95\% CI: $28,34)$ among mothers who had no history of CSA.

\section{Risk and Protective Factors for Postpartum Depression}

Both bivariate and multivariable logistic regression analyses were performed. According to the bivariate logistic regression analysis results; participants' age of $<25$ years $(\mathrm{COR}=2.0 ; 95 \% \mathrm{CI}: 1.3,3.2)$, family size of $3-5(\mathrm{COR}=$ 0.5 ; 95\% CI: $0.3,0.9)$, living alone $(\mathrm{COR}=1.9 ; 95 \% \mathrm{CI}$ : 1.3,2.7), alcohol use $(\mathrm{COR}=2.3 ; 95 \% \mathrm{CI}: 1.8,3.1)$, history of CSA (COR $=2.8 ; 95 \% \mathrm{CI}: 1.9,4.1)$, joblessness $(\mathrm{COR}=1.6 ; 95 \% \mathrm{CI}: 1.2,2.1)$, grown up with biological mothers $(\mathrm{COR}=0.5 ; 95 \% \mathrm{CI}: 0.4,0.8)$, having unplanned pregnancy $(\mathrm{COR}=1.6 ; 95 \% \mathrm{CI}: 1.1,2.2)$ and owing delivery via $\mathrm{C} / \mathrm{S}(\mathrm{COR}=1.4 ; 95 \% \mathrm{CI}: 1.1,1.8)$ were associated with PPD. On the other hand, the multivariable logistic regression analysis result show that younger age (ie, $<25$ years $[\mathrm{AOR}=3.1 ; 95 \% \mathrm{CI}: 1.9,5.3]$ and $25-34$ years $[\mathrm{AOR}=2.0 ; 95 \% \mathrm{CI}: 1.3,3.2])$, family size of $>5$ $(\mathrm{AOR}=2.5 ; 95 \% \mathrm{CI}: 1.1,5.7)$, alcohol use $(\mathrm{AOR}=2.2$; 95\% CI: 1.6, 2.9), history of CSA (AOR $=2.8 ; 95 \% \mathrm{CI}$ : $1.9,4.27)$ and joblessness (AOR $=1.4 ; 95 \% \mathrm{CI}: 1.1,1.9)$ were risk factors for PPD. Whereas, growing up with biological mothers $(\mathrm{AOR}=0.5 ; 95 \% \mathrm{CI}: 0.4,0.8)$ was a protective factor for PPD (Table 3).

\section{Discussion}

Maternal mental health is a very essential component of health from multi-dimensional perspectives within the family and the community at large. Unfortunately, it can be affected by enormous psychosocial stressors including CSA. ${ }^{1,37}$ Epigenetic changes in gene expression which lead to PPD are initiated via environmental influences and represent a cross-talk between environment and genetics. ${ }^{43}$ Thus, environmental factors, such as CSA, socio-cultural roles, psychological attributes, and coping skills are known to contribute to PPD. ${ }^{44}$ These environmental factors in turn could vary across countries and settings. In this perspective, the link between PPD and CSA has been well address in the developed world. However, the effect of CSA on PPD has not been adequately investigated in low income countries, including Ethiopia. Thus, the current study aimed at assessing PPD and associated factors among postnatal women in care in public health facilities of Bahir Dar city, northwest Ethiopia. This study also paid emphasis to evaluate the effect of early CSA on PPD. Accordingly, the prevalence of PPD in the study settings was found to be high and its risk factors include participants age of $<25$ years and 25-34 years, family size of $>5$, alcohol use, history of CSA and joblessness. On the other hand, growing up with biological mothers was found to be a protective factor of PPD.

The prevalence of PPD was found to be $33.8 \%$ (95\% CI: 31,37$)$. This implies that about one third (ie, one out of three) of the respondents developed PPD. Moreover, the prevalence of PPD was much higher among mothers having a history of CSA than those with no history of CSA (55.3\% versus $30.8 \%$ ). The magnitude of PPD (ie, 33.8\%) in the current study is similar to what was reported in South Africa(34.7\%). ${ }^{20}$ However, the prevalence of PPD in our study is higher than the results of previous studies conducted in low- and lower-middle-income countries $(19.8 \%),{ }^{21}$ in India $(23 \%),{ }^{27}$ in Pakistan $(28 \%),{ }^{28}$ in Zimbabwe(16\%), ${ }^{29}$ and in Uganda(6.1\%). ${ }^{30}$ The high 
Table I Socio-Demographic Characteristics of the Mothers Who Had No History of Childhood Sexual Abuse ( $\mathrm{n}=865)$ and Who Had History of Childhood Sexual Abuse ( $=123)$

\begin{tabular}{|c|c|c|c|c|c|c|c|}
\hline \multirow[t]{2}{*}{ Characteristics } & \multicolumn{2}{|l|}{ Overall } & \multicolumn{2}{|l|}{ Abused } & \multicolumn{2}{|c|}{ Non-Abused } & \multirow[t]{2}{*}{ p-value } \\
\hline & Number & Percent & Number & Percent & Number & Percent & \\
\hline \multicolumn{8}{|l|}{ Age (years) } \\
\hline$<25$ & 202 & 20.4 & 23 & 18.7 & 179 & 20.7 & 0.022 \\
\hline $25-34$ & 616 & 62.3 & 68 & 55.3 & 548 & 63.4 & \\
\hline$>34$ & 170 & 17.2 & 32 & 26.0 & 138 & 16.0 & \\
\hline \multicolumn{8}{|l|}{ Education level } \\
\hline Unable to read and write & 158 & 16.0 & 29 & 23.5 & 129 & 14.9 & 0.040 \\
\hline Primary & 125 & 12.7 & 12 & 9.8 & 113 & 13.1 & \\
\hline High school and above & 705 & 71.3 & 82 & 66.7 & 623 & 72.0 & \\
\hline \multicolumn{8}{|l|}{ Job } \\
\hline Jobless & 388 & 39.3 & 41 & 33.3 & 347 & 40.1 & 0.167 \\
\hline Has job & 600 & 60.7 & 82 & 66.7 & 518 & 59.9 & \\
\hline \multicolumn{8}{|l|}{ Living conditions } \\
\hline Alone & 138 & 14.0 & 29 & 23.6 & 109 & 12.6 & 0.002 \\
\hline With family & 850 & 86.0 & 94 & 76.4 & 756 & 87.4 & \\
\hline \multicolumn{8}{|l|}{ Current marital status } \\
\hline Married & 806 & 81.6 & 40 & 32.5 & 723 & 83.6 & 0.000 \\
\hline Unmarried & 182 & 18.4 & 83 & 67.5 & 142 & 16.4 & \\
\hline \multicolumn{8}{|l|}{ Family size } \\
\hline 1 to 2 & 46 & 4.7 & 8 & 6.5 & 38 & 4.4 & \\
\hline 3 to 5 & 870 & 88.1 & 95 & 77.2 & 775 & 89.6 & \\
\hline$>5$ & 71 & 7.3 & 20 & 16.3 & 52 & 6.0 & \\
\hline \multicolumn{8}{|l|}{ Grow-up with } \\
\hline With biological mother & 623 & 63.1 & 67 & 54.5 & 556 & 64.3 & 0.007 \\
\hline With step-mother & 179 & 18.1 & 20 & 16.3 & 159 & 18.4 & \\
\hline With relatives & 186 & 18.8 & 36 & 29.2 & 150 & 17.3 & \\
\hline Age at first marriage & & & & & & & 0.829 \\
\hline$<20$ years & 537 & 54.4 & 70 & 56.9 & 467 & 54.1 & \\
\hline 21 to 25 years & 360 & 36.5 & 42 & 34.2 & 318 & 36.8 & \\
\hline 26 and above & 90 & 9.1 & 11 & 8.9 & 79 & 9.1 & \\
\hline \multicolumn{8}{|l|}{ Wealth (relative) } \\
\hline Lower & 302 & 30.6 & 46 & 37.4 & 256 & 29.6 & \\
\hline Middle & 654 & 66.2 & 75 & 61.0 & 579 & 66.9 & \\
\hline Higher & 32 & 3.2 & 2 & 1.6 & 30 & 3.5 & \\
\hline
\end{tabular}

burden of PPD in the current study could be due to the high magnitude of stressful life events and family related problems among study participants. For example, about $439(44.4 \%)$ of them gave birth through $\mathrm{C} / \mathrm{S}, 538$ $(54.5 \%)$ of them reported that their husbands were sexually cheaters, $273(27.6 \%)$ of them had a history of abortion, and 365 (36.9\%) of them did not grow up with their biological mother. In this perspective, empirical evidence showcases that many of the risk factors for PPD fall under the umbrella of stress. ${ }^{43}$ In addition, variation in 
Table 2 Psychosocial Factors Among Mothers Who Had No History of Childhood Sexual Abuse ( $\mathrm{n}=865)$ and Who Had History of Childhood Sexual Abuse ( $\mathrm{N}=123)$

\begin{tabular}{|c|c|c|c|c|c|c|c|}
\hline \multirow[t]{2}{*}{ Characteristics } & \multicolumn{2}{|l|}{ Overall } & \multicolumn{2}{|l|}{ Abused } & \multicolumn{2}{|c|}{ Non-Abused } & \multirow[t]{2}{*}{ p-value } \\
\hline & Number & Percent & Number & Percent & Number & Percent & \\
\hline Mode of delivery & & & & & & & 0.028 \\
\hline Cesarean section & 439 & 44.4 & 66 & 53.7 & 373 & 43.1 & \\
\hline Vaginal delivery & 549 & 55.6 & 57 & 46.3 & 492 & 56.9 & \\
\hline History of abortion & & & & & & & 0.195 \\
\hline Yes & 273 & 27.6 & 40 & 32.5 & 233 & 26.9 & \\
\hline No & 715 & 72.4 & 80 & 67.8 & 632 & 73.1 & \\
\hline Social support & & & & & & & 0.053 \\
\hline Poor & 207 & 21.0 & 36 & 29.2 & $17 \mid$ & 19.8 & \\
\hline Moderate & 660 & 66.8 & 74 & 60.2 & 586 & 67.7 & \\
\hline Good & 121 & 12.2 & 13 & 10.6 & 108 & 12.5 & \\
\hline History of depression & & & & & & & \\
\hline Yes & 79 & 8.0 & 6 & 4.9 & 73 & 8.4 & \\
\hline No & 909 & 92.0 & 117 & 95.1 & 792 & 91.6 & \\
\hline Current pregnancy & & & & & & & 0.000 \\
\hline Planned & 836 & 84.6 & 83 & 67.5 & 753 & 87.1 & \\
\hline Unplanned & 152 & 15.4 & 40 & 32.5 & 112 & 12.9 & \\
\hline Self-ability to care child & & & & & & & 0.000 \\
\hline Able to care & 760 & 76.9 & 79 & 64.2 & 681 & 78.7 & \\
\hline Unable to care & 228 & 23.1 & 44 & 35.8 & 184 & 21.3 & \\
\hline Sexual cheater husband & & & & & & & \\
\hline Yes & 538 & 54.5 & 94 & 76.4 & 444 & 51.3 & 0.000 \\
\hline No & 450 & 45.5 & 29 & 23.6 & 421 & 48.7 & \\
\hline Physical illness & & & & & & & 0.000 \\
\hline Yes & 217 & 22.0 & 59 & 48.0 & 158 & 18.3 & \\
\hline No & 771 & 78.0 & 64 & 52.0 & 707 & 81.7 & \\
\hline Alcohol use & & & & & & & 0.234 \\
\hline Yes & 323 & 32.7 & 46 & 37.4 & 277 & 32.0 & \\
\hline No & 665 & 67.3 & 77 & 62.6 & 588 & 68.0 & \\
\hline Smoking & & & & & & & \\
\hline Yes & 10 & 1.0 & 2 & 1.6 & 8 & 0.9 & \\
\hline No & 978 & 99.0 & $12 \mid$ & 98.4 & 857 & 99.1 & \\
\hline Khat chewing & & & & & & & \\
\hline Yes & 16 & 1.6 & 7 & 5.7 & 9 & 1.0 & \\
\hline No & 972 & 98.4 & 116 & 94.3 & 856 & 99.0 & \\
\hline Cannabis use & & & & & & & \\
\hline Yes & 16 & 1.6 & 3 & 2.4 & 13 & 1.5 & \\
\hline No & 972 & 98.4 & 120 & 97.6 & 852 & 98.5 & \\
\hline
\end{tabular}

study settings, socio-demographic characteristics of the respondents, and sample size across studies could contribute to the observed discrepancy. In contrast, other earlier studies have reported high prevalence of depression symptoms (reached up to $60.8 \%$ ) among certain postpartum mothers. ${ }^{15,16}$ Of course, sample size difference, setting difference, postpartum depression scoring cutoff point difference, time frame for inclusion mothers after delivery 
Table 3 Factors Association with Postpartum Depression Among Postpartum Mothers

\begin{tabular}{|c|c|c|c|}
\hline $\begin{array}{l}\text { Explanatory } \\
\text { Variables }\end{array}$ & $\begin{array}{l}\text { COR }(95 \% \\
\text { Cl) }\end{array}$ & $\begin{array}{l}\text { AOR }(95 \% \\
\mathrm{Cl})\end{array}$ & p-value \\
\hline \multicolumn{4}{|l|}{ Age (years) } \\
\hline$<25$ & $2.0(1.3,3.2)^{*}$ & $3.1(1.9,5.3)$ & 0.000 \\
\hline 25 to 34 & I.3 $(0.9$, I.9) & $2.0(1.3,3.2)$ & 0.002 \\
\hline$>34$ & 1.00 & 1.00 & \\
\hline \multicolumn{4}{|l|}{ Family size } \\
\hline I to 2 & 1.00 & 1.00 & \\
\hline 3 to 5 & $0.5(0.3,0.9)^{*}$ & $0.6(0.3, I . I)$ & 0.079 \\
\hline$>5$ & I.7 $(0.8,3.6)$ & $2.5(1.1,5.7)$ & 0.031 \\
\hline \multicolumn{4}{|l|}{ Living condition } \\
\hline With family & 1.00 & 1.00 & \\
\hline Alone & $1.9(1.3,2.7)^{*}$ & $0.1 \mathrm{I}(0.5, \mathrm{I} . \mathrm{I})$ & 0.721 \\
\hline \multicolumn{4}{|l|}{ Grow-up } \\
\hline $\begin{array}{l}\text { With biological } \\
\text { mother }\end{array}$ & $0.5(0.4,0.8)^{*}$ & $0.5(0.4,0.8)$ & 0.005 \\
\hline With step-mother & $1.3(0.9,1.8)$ & $1.2(0.8,1.7)$ & $0.34 I$ \\
\hline With relatives & 1.00 & 1.00 & \\
\hline \multicolumn{4}{|l|}{ Alcohol use } \\
\hline Yes & $2.3(1.8,3.1)^{*}$ & $2.2(1.6,2.9)$ & 0.000 \\
\hline No & 1.00 & 1.00 & \\
\hline \multicolumn{4}{|c|}{ History of childhood sexual abuse } \\
\hline Abused & $2.8(1.9,4.1)^{*}$ & $2.8(1.9,4.3)$ & 0.000 \\
\hline Non-abused & 1.00 & 1.00 & \\
\hline \multicolumn{4}{|l|}{ Pregnancy } \\
\hline Planned & 1.00 & 1.00 & \\
\hline Unplanned & $1.6(I .1,2.2)^{*}$ & $1.0(0.6,1.4)$ & 0.853 \\
\hline \multicolumn{4}{|l|}{ Route of delivery } \\
\hline Cesarean Section & $\mathrm{I} .4(1.0, \mathrm{I} .8)^{*}$ & $1.3(10,1.8)$ & 0.058 \\
\hline Vaginal delivery & 1.00 & 1.00 & \\
\hline \multicolumn{4}{|l|}{ Job } \\
\hline Yes & 1.00 & 1.00 & \\
\hline No & $1.6(1.2,2.1)^{*}$ & $1.4(1.1,1.9)$ & 0.028 \\
\hline
\end{tabular}

Note: ${ }^{*} \mathrm{p}$ value $<0.05$ and 1.00 (Reference).

and others socio-cultural variations may be responsible for this discrepancy.

Mental health is not static, and there is a rough association between CSA and late onset of mental illness. ${ }^{45,46}$ In this study, for example, PPD was significantly higher among mothers who had a history of CSA than mothers who had no history of CSA (55.3\% versus $30.8 \%$ ). Our finding is consistent with previous studies which justify that women's mental health status is adversely affected by gender-based violence. CSA could be a risk for the development of adulthood mental illness. ${ }^{37,47}$ This might be associated with numerous psychopathology including mental illness in later adulthood life, ${ }^{11}$ their ability to care for their child, give affection, level of self-esteem and intimate relationships with their families. ${ }^{1,11,48}$

Psychological trauma due to sexual abuse is common in Ethiopia. Existing evidences points out that about 59\% and $49 \%$ of the women have suffered from sexual violence and physical violence by a partner, respectively, at some point in their lives, in Ethiopia. Of these, about $44 \%$ and $29 \%$ reported that they experience sexual and partner violence annually. ${ }^{13}$ In our study, PPD was found to be higher in mothers who had CSA than in mothers who had not had CSA. Women with history of CSA are more likely to have a harsh life and may be exposed to early marriage, unwanted pregnancy, sexually transmitted diseases and maternal duties under age of 18 years. ${ }^{14}$ This may lead mothers to develop PPD during postpartum period and to feeling inadequate to be a good care giver. ${ }^{35}$

According to the current study finding, the odds of developing PPD were higher among women with the age of $<25$ years and 25-34 years than those women with the age of $\geq 35$ years. Being a mother at younger age may have a negative psychosocial effect on their social life than being a mother at older age ( $\geq 35$ years in this study) and supported by previous studies. ${ }^{49}$ In our culture, mothers have different social duties and responsibilities after marriage and children. So, after a girl has a child at a younger age, she may not be involved in her usual lifestyle as her friends do. After being a mother, every lifestyle may be changed and this change in life may bring about a feeling of depression. However, the results of some previous studies contradict the association between early maternity and PPD. ${ }^{19,50}$

Postpartum depression had a significant association with childhood separation and growning up with their biological mother. In our study, growing up with biological mothers is found to be a protective factor for PPD. Accordingly, mothers who grow up with their biological mothers had $46 \%$ more chance to get protection from developing PPD than mothers who had grown up with step-mothers. Mothers who had grown up with their biological mothers have better social support and intimate relationship throughout their childhood. On the other 
hand, perceived maternal and paternal care during childhood (over protection or under protection) in mothers had a significant influence on developing late PPD. ${ }^{51}$

In the current study, joblessness is found to be a risk factor of PPD. Thus, jobless mothers were 1.38 times more likely to develop PPD compared with a reference group. The significant independent association between joblessness and PPD could be due to the fact that women with no job might develop a fear of being unable to take care of the child sufficiently as a result of shortage of income to do so. As a result, they might experience loss of self- confidence and worry about the means of getting money.

Our study also aimed to assess the effect of CSA on PPD and the result exhibited that CSA is an independent risk factor for PPD. Hence, mothers having history of CSA were 2.83 times more probable to develop PPD as compared to mothers with no history of CSA. The association could be due to the reality that CSA may have a negative association with self-confidence, work productivity and related social responsibilities. Moreover, CSA is a contributing factor for lower levels of education, unemployment, poor earnings, and fewer assets as adults. Evidence shows that women who had a history of CSA could experience large and enduring economic consequences. ${ }^{52}$ Studies also report that there is up to $14 \%$ gap of employment between individuals with histories of abuse and their controls, ${ }^{53}$ and thus depression may be a result of joblessness.

Substance use was found to be a common practice among postpartum women. Even if female substance users have a social devalue crises in Ethiopian culture, alcohol use had a significant association with PPD in our study. Substance use is a risk for depression in many populations and the direct effect of alcohol may have an impact on mothers' mood. This finding is supported by earlier studies which reported that those mothers who drink alcohol had more depression symptoms than non-drinkers. ${ }^{54}$ This finding is also aligned with the result of previous studies in which women who had experience of CSA have a risk of later development of substance abuse and may develop PPD. ${ }^{55}$ Even though the relationship between substance use and CSA is mediated by other psychiatric conditions such as anxiety and depressive disorders, CSA can be a risk factor for substance abuse among trauma survival mothers. ${ }^{56}$ Alcohol consumption not only affects maternal mental health, but also affects their child mental or developmental wellness. Even at very low levels alcohol consumption during early pregnancy period may have a negative and adverse effect on childhood mental health.

The current study also come up with a result that showed a significant association between family size and PPD, in which larger family size was found to be a risk factor for PPD. Thus, the odds of experiencing PPD were 2.50 times higher among postnatal mothers who had more than five family members, than those with $\leq 2$ family members. The association could be explained via their level of commitment in which mothers with larger family size may take higher level of commitment to care for a large family member in one family and this in turn may cause feeling of stress and depression.

\section{Limitation}

This study was a cross-sectional study and unable to see the exact cause-effect association between CSA and PPD. In most parts of Ethiopia, particularly in Amhara region, blaming oneself and taking the risk for others' mistake is considered as a good culture and is believed to be a feature of humbleness and politeness. Thus, one of the 10 items of EPDS "I have blamed myself unnecessarily when things went wrong" could overestimate the magnitude of PPD. In addition, according to the Orthodox Christian religion, there is a spiritual program called "Christina" on the 40th day for male babies and 80th day for female babies after child birth. As women were asked at about 6-8 weeks of postpartum (ie, just immediately following the "Christina" Program for male infants), their reply to the EPDS items could be affected.

\section{Conclusion}

The overall prevalence of PPD was higher than many other previous studies. There was a notable maternal mental health problem in the study settings and a significantly higher burden was observed among mothers with history of CSA. Majority of the risk factors of PPD were linked to poor socio-demographic and psychosocial profiles such as CSA, alcohol use, joblessness and large family size. Thus, more holistic in-depth understanding of the occurrence of PPD, controlling CSA, and other psychosocial determinants would improve maternal mental wellness.

\section{Abbreviations}

$\mathrm{AOR}$, adjusted odd ratios; $\mathrm{COR}$, crude odd ratios; $\mathrm{CI}$, confidence interval; CSA, childhood sexual abuse; EPDS, Edinburg Postnatal Depression Scale; PPD, postpartum depression; $\mathrm{C} / \mathrm{S}$, Cesarean section. 


\section{Data Sharing Statement}

The authors declare that the data regarding this manuscript can be accessed as per the request of any interested body and can be accessed by emailing to the corresponding author using "muhabawshumye@gmail.com”.

\section{Ethical Approval and Consent}

Ethical clearance was obtained from the Ethical Review Committee of College of Medicine and Health Sciences, Bahir Dar University. Formal permission letter was obtained from administrative of the hospitals. Written informed consent was then obtained from each participant after clear explanation of the purpose of the study. Confidentiality and anonymity was maintained. Mothers who had PPD were linked with psychiatric service. The authors would like to confirm that this study was conducted in accordance with the Declaration of Helsinki.

\section{Consent for Publication}

Not applicable.

\section{Acknowledgment}

The authors want to acknowledge Bahir Dar University for the grant and ethical letter. We are also very grateful to the study participants and data collectors for their genuine contribution.

\section{Author Contributions}

All authors made a significant contribution to the work reported, whether that is in the conception, study design, execution, acquisition of data, analysis and interpretation, or in all these areas; took part in drafting, revising or critically reviewing the article; gave final approval of the version to be published; have agreed on the journal to which the article has been submitted; and agree to be accountable for all aspects of the work.

\section{Funding}

This study was funded by the Bahir Dar University, Grant No. $2017 / 02$.

\section{Disclosure}

The authors report no conflicts of interest in this work.

\section{References}

1. Fergusson DM, Horwood LJ, Lynskey MT. Childhood sexual abuse and psychiatric disorder in young adulthood: II. Psychiatric outcomes of childhood sexual abuse. J Am Acad Child Adolesc Psychiatry. 1996;35(10):1365-1374. doi:10.1097/00004583-199610000-00024

2. Akmatov MK. Child abuse in 28 developing and transitional countries-results from the multiple indicator cluster surveys. Int J Epidemiol. 2011;40(1):219-227. doi:10.1093/ije/dyq168

3. Gilbert R, Widom CS, Browne K, et al. Burden and consequences of child maltreatment in high-income countries. Lancet. 2009;373 (9657):68-81. doi:10.1016/S0140-6736(08)61706-7

4. Weiss EL, Longhurst JG, Mazure CM. Childhood sexual abuse as a risk factor for depression in women: psychosocial and neurobiological correlates. Am J Psychiatry. 1999;156(6):816-828. doi:10.1176/ ajp.156.6.816

5. Resick PA, Schnicke M. Cognitive Processing Therapy for Rape Victims: A Treatment Manual. Sage; 1993.

6. Buist A, Barnett B. Childhood sexual abuse: a risk factor for postpartum depression? Aust N Z J Psychiatry. 1995;29(4):604-608. doi:10.3109/00048679509064974

7. Leigh B, Milgrom J. Risk factors for antenatal depression, postnatal depression and parenting stress. BMC Psychiatry. 2008;8(1):24. doi:10.1186/1471-244X-8-24

8. Leeners B, Richter-Appelt H, Imthurn B, et al. Influence of childhood sexual abuse on pregnancy, delivery, and the early postpartum period in adult women. J Psychosom Res. 2006;61(2):139-151. doi:10.1016/ j.jpsychores.2005.11.006

9. Schuetze P, Eiden RD. The relationship between sexual abuse during childhood and parenting outcomes: modeling direct and indirect pathways. Child Abuse Negl. 2005;29(6):645-659. doi:10.1016/j. chiabu.2004.11.004

10. Beitchman JH, Zucker KJ, Hood JE, et al. A review of the long-term effects of child sexual abuse. Child Abuse Negl. 1992;16(1):101-118. doi:10.1016/0145-2134(92)90011-F

11. Mullen PE, Martin JL, Anderson JC, et al. Childhood sexual abuse and mental health in adult life. $B r \quad J$ Psychiatry. 1993;163 (6):721-732. doi:10.1192/bjp.163.6.721

12. Gelaye B, Arnold D, Williams MA, et al. Depressive symptoms among female college students experiencing gender-based violence in Awassa, Ethiopia. J Interpers Violence. 2009;24(3):464-481. doi:10.1177/0886260508317173

13. Gossaye Y, Deyessa N, Berhane Y, et al. Women's health and life events study in rural Ethiopia. Ethiop J Health Dev. 2003;17(5).

14. Worku D, Gebremariam A, Jayalakshmi S. Child sexual abuse and its outcomes among high school students in southwest Ethiopia. Trop Doct. 2006;36(3):137-140. doi:10.1258/004947506777978325

15. Affonso DD, De AK, Horowitz JA, et al. An international study exploring levels of postpartum depressive symptomatology. J Psychosom Res. 2000;49(3):207-216. doi:10.1016/S00223999(00)00176-8

16. Halbreich U, Karkun S. Cross-cultural and social diversity of prevalence of postpartum depression and depressive symptoms. J Affect Disord. 2006;91(2-3):97-111. doi:10.1016/j.jad.2005.12.051

17. Kok L, Chan P, Ratnam S. Postnatal depression in Singapore women. Singapore Med J. 1994;35:33.

18. Gavin NI, Gaynes BN, Lohr KN, et al. Perinatal depression: a systematic review of prevalence and incidence. Obstet Gynecol. 2005;106(5, Part 1):1071-1083. doi:10.1097/01.AOG.0000183597.31630.db

19. O'hara MW, Swain AM. Rates and risk of postpartum depression-a meta-analysis. Int Rev Psychiatry. 1996;8(1):37-54. doi:10.3109/ 09540269609037816

20. Cooper PJ, Tomlinson M, Swartz L, et al. Post-partum depression and the mother-infant relationship in a South African peri-urban settlement. Br J Psychiatry. 1999;175(6):554-558. doi:10.1192/ bjp.175.6.554 
21. Fisher J, Mello M, Patel V, et al. Prevalence and determinants of common perinatal mental disorders in women in low-and lower-middle-income countries: a systematic review. Bull World Health Organ. 2012;90(2):139-149. doi:10.2471/BLT.11.091850

22. Tolossa T, Fetensa G, Yilma MT, et al. Postpartum depression and associated factors among postpartum women in Ethiopia: a systematic review and meta-analysis, 2020. Public Health Rev. 2020;41(1):21. doi:10.1186/s40985-020-00136-3

23. Abebe A, Tesfaw G, Mulat H, et al. Postpartum depression and associated factors among mothers in Bahir Dar Town, Northwest Ethiopia. Ann Gen Psychiatry. 2019;18(1):19. doi:10.1186/s12991-019-0244-4

24. Wubetu AD, Engidaw NA, Gizachew KD. Prevalence of postpartum depression and associated factors among postnatal care attendees in Debre Berhan, Ethiopia, 2018. BMC Pregnancy Childbirth. 2020;20 (1):189. doi:10.1186/s12884-020-02873-4

25. Abadiga M, Ciccozzi M. Magnitude and associated factors of postpartum depression among women in Nekemte town, East Wollega zone, west Ethiopia, 2019: a community-based study. PLoS One. 2019;14(11):e0224792. doi:10.1371/journal.pone.0224792

26. Azale T, Fekadu A, Hanlon C. Postpartum depressive symptoms in the context of high social adversity and reproductive health threats: a population-based study. Int $J$ Ment Health Syst. 2018;12. doi:10.1186/s13033-018-0219-x

27. Patel V, Rodrigues M, DeSouza N. Gender, poverty, and postnatal depression: a study of mothers in Goa, India. Am J Psychiatry. 2002;159(1):43-47. doi:10.1176/appi.ajp.159.1.43

28. Rahman A, Iqbal Z, Harrington R. Life events, social support and depression in childbirth: perspectives from a rural community in the developing world. Psychol Med. 2003;33(7):1161-1167. doi:10.1017/ S0033291703008286

29. Nhiwatiwa S, Patel V, Acuda W. Predicting postnatal mental disorder with a screening questionnaire: a prospective cohort study from Zimbabwe. J Epidemiol Community Health. 1998;52(4):262-266. doi:10.1136/jech.52.4.262

30. Nakku J, Nakasi G, Mirembe F. Postpartum major depression at six weeks in primary health care: prevalence and associated factors. Afr Health Sci. 2007;6(4).

31. Zaidi F, Nigam A, Anjum R, et al. Postpartum depression in women: a risk factor analysis. J Clin Diagn Res. 2017;11(8):Qc13-qc16. doi: $10.7860 / j \mathrm{jdr} / 2017 / 25480.10479$

32. Khalifa DS, Glavin K, Bjertness E, et al. Determinants of postnatal depression in Sudanese women at 3 months postpartum: a crosssectional study. BMJ Open. 2016;6(3):e009443. doi:10.1136/bmjopen-2015-009443

33. Levitan RD, Parikh SV, Lesage AD, et al. Major depression in individuals with a history of childhood physical or sexual abuse: relationship to neurovegetative features, mania, and gender. $\mathrm{Am}$ J Psychiatry. 1998;155(12):1746-1752. doi:10.1176/ajp.155.12.1746

34. Benedict MI, Paine LL, Paine LA, et al. The association of childhood sexual abuse with depressive symptoms during pregnancy, and selected pregnancy outcomes. Child Abuse Negl. 1999;23 (7):659-670. doi:10.1016/S0145-2134(99)00040-X

35. Horwitz AV, Widom CS, McLaughlin J, et al. The impact of childhood abuse and neglect on adult mental health: a prospective study. J Health Soc Behav. 2001;42(2):184-201. doi:10.2307/3090177

36. Bifulco A, Brown GW, Adler Z. Early sexual abuse and clinical depression in adult life. $B r J$ Psychiatry. 1991;159(1):115-122. doi:10.1192/bjp.159.1.115

37. Bifulco A, Bernazzani O, Moran PM, et al. The childhood experience of care and abuse questionnaire (CECA.Q): validation in a community series. Br J Clin Psychol. 2005;44(4):563-581. doi:10.1348/014466505x35344
38. Mekuria A, Nigussie A, Abera M. Childhood sexual abuse experiences and its associated factors among adolescent female high school students in Arbaminch town, Gammo Goffa zone, Southern Ethiopia: a mixed method study. BMC Int Health Hum Rights. 2015;15(1):21. doi:10.1186/s12914-015-0059-6

39. Cox JL, Holden JM, Sagovsky R. Detection of postnatal depression. development of the 10-item edinburgh postnatal depression scale. $\mathrm{Br}$ J Psychiatry. 1987;150(6):782-786. doi:10.1192/bjp.150.6.782

40. Tsai AC, Scott JA, Hung KJ, et al. Reliability and validity of instruments for assessing perinatal depression in African settings: systematic review and meta-analysis. PLoS One. 2013;8(12):e82521. doi:10.1371/journal.pone. 0082521

41. Bøen H. Characteristics of senior centre users-and the impact of a group programme on social support and late-life depression. Nor Epidemiol. 2012;22(2). doi:10.5324/nje.v22i2.1574

42. Payne JL, Maguire J. Pathophysiological mechanisms implicated in postpartum depression. Front Neuroendocrinol. 2019;52:165-180. doi:10.1016/j.yfrne.2018.12.001

43. O'Hara MW, McCabe JE. Postpartum depression: current status and future directions. Annu Rev Clin Psychol. 2013;9(1):379-407. doi:10.1146/annurev-clinpsy-050212-185612

44. Fleming J, Mullen PE, Sibthorpe B, et al. The long-term impact of childhood sexual abuse in Australian women. Child Abuse Negl. 1999;23(2):145-159. doi:10.1016/S0145-2134(98)00118-5

45. Coid J, Petruckevitch A, Feder G, et al. Relation between childhood sexual and physical abuse and risk of revictimisation in women: a cross-sectional survey. Lancet. 2001;358(9280):450-454. doi:10.1016/S0140-6736(01)05622-7

46. Mullen PE, Fergusson DM. Childhood Sexual Abuse: An EvidenceBased Perspective. Sage Publications; 1999.

47. Kendler KS, Bulik CM, Silberg J, et al. Childhood sexual abuse and adult psychiatric and substance use disorders in women: an epidemiological and cotwin control analysis. Arch Gen Psychiatry. 2000;57(10):953-959. doi:10.1001/archpsyc.57.10.953

48. Segre LS, O'Hara MW, Arndt S, et al. The prevalence of postpartum depression. Soc Psychiatry Psychiatr Epidemiol. 2007;42 (4):316-321. doi:10.1007/s00127-007-0168-1

49. Beck CT. Predictors of postpartum depression: an update. Nurs Res. 2001;50(5):275-285. doi:10.1097/00006199-200109000-00004

50. Gotlib IH, Whiffen VE, Wallace PM, et al. Prospective investigation of postpartum depression: factors involved in onset and recovery. $J$ Abnorm Psychol. 1991;100(2):122. doi:10.1037/0021-843X.100.2.122

51. Bogar CB, Hulse-Killacky D. Resiliency determinants and resiliency processes among female adult survivors of childhood sexual abuse. J Couns Devel. 2006;84(3):318-327. doi:10.1002/j.1556-6678.2006. tb00411.x

52. Currie J, Spatz Widom C. Long-term consequences of child abuse and neglect on adult economic well-being. Child Maltreat. 2010;15 (2):111-120. doi:10.1177/1077559509355316

53. Barnet B, Duggan AK, Wilson MD, et al. Association between postpartum substance use and depressive symptoms, stress, and social support in adolescent mothers. Pediatrics. 1995;96(4):659-666.

54. Wilsnack SC, Vogeltanz ND, Klassen AD, et al. Childhood sexual abuse and women's substance abuse: national survey findings. $J$ Stud Alcohol. 1997;58(3):264-271. doi:10.15288/jsa.1997.58.264

55. Simpson TL, Miller WR. Concomitance between childhood sexual and physical abuse and substance use problems: a review. Clin Psychol Rev. 2002;22(1):27-77. doi:10.1016/S0272-7358(00)00088-X

56. Sayal K, Heron J, Golding J, et al. Prenatal alcohol exposure and gender differences in childhood mental health problems: a longitudinal population-based study. Pediatrics. 2007;119(2): e426-e34. doi:10.1542/peds.2006-1840 


\section{Publish your work in this journal}

The International Journal of Women's Health is an international, peerreviewed open-access journal publishing original research, reports, editorials, reviews and commentaries on all aspects of women's healthcare including gynecology, obstetrics, and breast cancer. The manuscript management system is completely online and includes a very quick and fair peer-review system, which is all easy to use. Visit http://www.dovepress.com/testimonials.php to read real quotes from published authors. 